\title{
Maltodextrin May Be a Promising Treatment Modality After Near- total Pancreatectomy in Infants Younger Than Six Months with Persistent Hyperinsulinism: A Case Report
}

\author{
(D) Yasemin Denkboy Öngen, (D) Erdal Eren, (D) Halil Sağlam \\ Bursa Uludağ University Faculty of Medicine, Department of Pediatric Endocrinology, Bursa, Turkey
}

\begin{abstract}
What is already known on this topic?
Congenital hyperinsulinism (CHI) is the most common cause of persistent hypoglycemia in newborns and infants. While several medical treatment agents are used to treat infants with $\mathrm{CHI}$, hypoglycemia management has been quite difficult to date.
\end{abstract}

\section{What this study adds?}

In those cases with $\mathrm{CHI}$, maltodextrin addition in the early period enables us to achieve more stable serum glucose. Maltodextrin addition also shortens the patient's discharge period, prevents complications, and protects the patient from treatment side effects. Continuous glucose monitoring systems help to manage the patients' follow-ups more efficiently in this group.

\begin{abstract}
Persistent hypoglycemia in infants with congenital hyperinsulinism (CHI) can be challenging in approximately half of these cases, even after undergoing a near-total pancreatectomy. While maltodextrin has been recommended in the nutritional management of CHI cases younger than six months, information regarding its efficacy in managing hypoglycemia are not yet clear. Here, we present a male infant with CHI who experienced persistent hypoglycemia even after undergoing a near-total pancreatectomy and despite multiple medical treatments. The infant's hypoglycemic episodes were successfully controlled by adding maltodextrin to his diet.

Keywords: Congenital hyperinsulinism, $A B C C 8$ gene, maltodextrin, near-total pancreatectomy, continue glucose monitoring systems
\end{abstract}

\section{Introduction}

Congenital hyperinsulinism (CHI) is the most common cause of persistent hypoglycemia in newborns and infants (1). While several medical treatment agents are used to treat these infants, the management of hypoglycemia has been quite difficult (2). It has been reported that persistent hypoglycemia can be seen in approximately $50 \%$ of cases with diffuse forms where a near-total pancreatectomy is performed (3).
Adzick et al. (4) reported that of the CHI cases who underwent a near-total pancreatectomy in their series, $31 \%$ had euglycemia, 20\% had hyperglycemia, and $49 \%$ had hypoglycemia requiring treatment. Moreover, it has been emphasized that surgery for the diffuse form is not a cure, but only helps hypoglycemia control.

Nutritional support is a critical factor, alongside medical treatment, in cases with $\mathrm{CHI}$. Frequent feeding with breast milk or formula is recommended for those who do not have oral intake problems (5). Uncooked cornstarch helps with
Address for Correspondence: Yasemin Denkboy Öngen MD, Bursa Uludağ University Faculty of Medicine, Department of Pediatric Endocrinology, Bursa, Turkey Phone: + 902242950533 E-mail: ydenkboyongen@uludag.edu.tr ORCID: orcid.org/0000-0002-5657-4260

${ }^{\circ}$ Copyright 2023 by Turkish Society for Pediatric Endocrinology and Diabetes

The Journal of Clinical Research in Pediatric Endocrinology published by Galenos Publishing House.
Conflict of interest: None declared Received: 03.05.2021 Accepted: 23.08.2021 
the stabilization of serum glucose in cases above six months, but it is not recommended for cases under six months because of its side effects. A small number of studies have reported on the use of maltodextrin (Malt Extract, Wakodo, Fantomalt Nutricia) added to breast milk or formula in the nutritional management of cases younger than six months. However, none of these studies clearly demonstrated the effectiveness of maltodextrin in controlling hypoglycemia (6).

In this article, we present a male infant with $\mathrm{CHI}$ who was experiencing persistent hypoglycemia even after undergoing a near-total pancreatectomy and despite multiple medical treatments and whose hypoglycemic episodes were successfully controlled by adding maltodextrin to his diet.

\section{Case Report}

A male patient was born with a weight of 4,020 grams in the $37^{\text {th }}$ week of pregnancy from a twenty-seven-year-old mother's first pregnancy. Critical blood samples taken due to seizure at the $3^{\text {rd }}$ hour of life revealed a serum glucose level of $22 \mathrm{mg} / \mathrm{dL}$, and a serum insulin level of $288 \mu \mathrm{U} / \mathrm{mL}$. An intravenous (IV) dextrose infusion at a rate of $6 \mathrm{mg} / \mathrm{kg} /$ min was initiated along with frequent breastfeeding. Due to persistent severe hypoglycemia in the follow-up, the IV infusion rate was gradually increased to $14 \mathrm{mg} / \mathrm{kg} / \mathrm{min}$. Due to the recurrence of hypoglycemia and the persistence of hyperinsulinism during hypoglycemia, $\mathrm{CHI}$ was considered a factor and diazoxide treatment was started at a dose of $10 \mathrm{mg} / \mathrm{kg} /$ day. Subsequently, his hypoglycemic episodes persisted and he was transported to our clinic on the $30^{\text {th }}$ day of life.

Preparation for surgery immediately began, diazoxide treatment was increased to $15 \mathrm{mg} / \mathrm{kg} / \mathrm{day}$, and octreotide was started at a dose of $5 \mathrm{mcg} / \mathrm{kg} /$ day and was gradually increased to $40 \mathrm{mcg} / \mathrm{kg} /$ day. Hypoglycemic episodes persisted during this treatment, and an IV infusion of glucagon was added. Facilities to carry out ${ }^{18} \mathrm{~F}$-L-DOPA PET imaging were not available and so could not be performed on our patient and transfer to another center was considered inappropriate. A near-total pancreatectomy $(95-98 \%$ resection) was performed on the $35^{\text {th }}$ day of life. Histopathological samples showed diffuse nesidioblastosis. Genetic analysis revealed a previously reported heterozygous C.2113 C > T mutation in the $A B C C 8$ gene which is known to be associated with diazoxide unresponsiveness.

After the surgery, octreotide and glucagon were continued, nifedipine was added, and the dextrose infusion was continued at a dose of $14 \mathrm{mg} / \mathrm{kg} / \mathrm{min}$. Despite full enteral nutrition and other parenteral treatments, the hypoglycemic episodes continued. Since the IV dextrose infusion could not be reduced, oral maltodextrin (1 measuring spoon of Fantomalt Nutricia contains 5 grams of $\mathrm{CHO}$ ) was added to each meal (12 times per day) at a total dose of 5 gram/ $\mathrm{kg} /$ day. After this, the addition of maltodextrin significantly controlled the patient's hypoglycemic episodes, and dextrose support was gradually decreased. Dextrose treatment was discontinued on the $7^{\text {th }}$ day following the addition of maltodextrin, and the patient was discharged.

Serum glucose monitoring was enabled using a continuous glucose monitoring system (CGMS) (Medtronic Guardian Connect CGM, Ca, USA) during both the inpatient and outpatient periods. This system was used off-label after receiving informed consent from the parents to monitor glucose variability in order to prevent hypoglycemia using trend arrows, and to improve the efficacy of treatments. CGMS of the patient revealed that the hypoglycemic episodes decreased significantly after the addition of maltodextrin (Figures 1 and 2). It was noticed that the percentage of serum glucose, which was below $70 \mathrm{mg} / \mathrm{dL}$ per day, decreased significantly after the addition of maltodextrin.

Glucagon and nifedipine treatments were discontinued after maltodextrin treatment, in the first and the fourth months, respectively. The octreotide dose was reduced to $14 \mathrm{mcg} /$ $\mathrm{kg} / \mathrm{day}$.

The patient's neurological examination was comparable to his peers, while his body weight was $14 \mathrm{~kg}$ [standard deviation score (SDS): 2.63], his height was $84 \mathrm{~cm}$ (SDS: 2.31), his body mass index was 19.8 (SDS: 1.5) and his head circumference was $47 \mathrm{~cm}$ (SDS: -0.01) at the age of 12 months. He is still receiving octreotide and maltodextrin treatment while not experiencing any hypoglycemic episodes.

\section{Discussion}

$\mathrm{CHI}$ is a rare glucose metabolism disease which most frequently causes persistent hypoglycemia in the neonatal period. Early diagnosis is essential in order to prevent neurological damage due to hypoglycemia (7). It is emphasized that frequent feeding with high-caloric carbohydrates can reduce hypoglycemia attacks (5). Xu et al. (6) stated that maltodextrin, a glucose polymer, can be used in the first six months of life. In contrast, uncooked corn starch is not used for the first six months due to its side effects. Cappella et al. (8) reported that adding maltodextrin to the diet instead of increasing IV glucose infusion is an effective procedure in cases of CHI. De Cosio and Thornton 
(9) recommended that patients with $\mathrm{CHI}$ should be supported with maltodextrin.

In the literature, a limited number of articles regarding maltodextrin use in $\mathrm{CHI}$ were found. In one report, it was stated that maltodextrin was given to $4 \mathrm{CHI}$ patients without any explanation regarding its efficacy (10).

Although maltodextrin is one of the most commonly known high-calorie formulae already being used in the feeding plans of $\mathrm{CHI}$ patients, the efficacy of maltodextrin on the hypoglycemic control of patients with CHI has not yet been studied in detail. There is no data on how adding maltodextrin to the diet effects the course of hypoglycemic episodes, the dosage, the feeding intervals or CGMS reports. Meanwhile, the possible side effects of maltodextrin are weight gain, gas, bloating and allergic reactions; however, none of these side effects were observed in our case (11).

In our case, the maltodextrin addition enabled us to achieve more stable serum glucose, to change the treatment modalities and to shorten the discharge period of the patient. CGMS also helped us to manage the patient's in/outpatient follow-ups more efficiently. The importance and efficacy of adding maltodextrin in the early period of hypoglycemia management was demonstrated in this CHI case by CGMS.

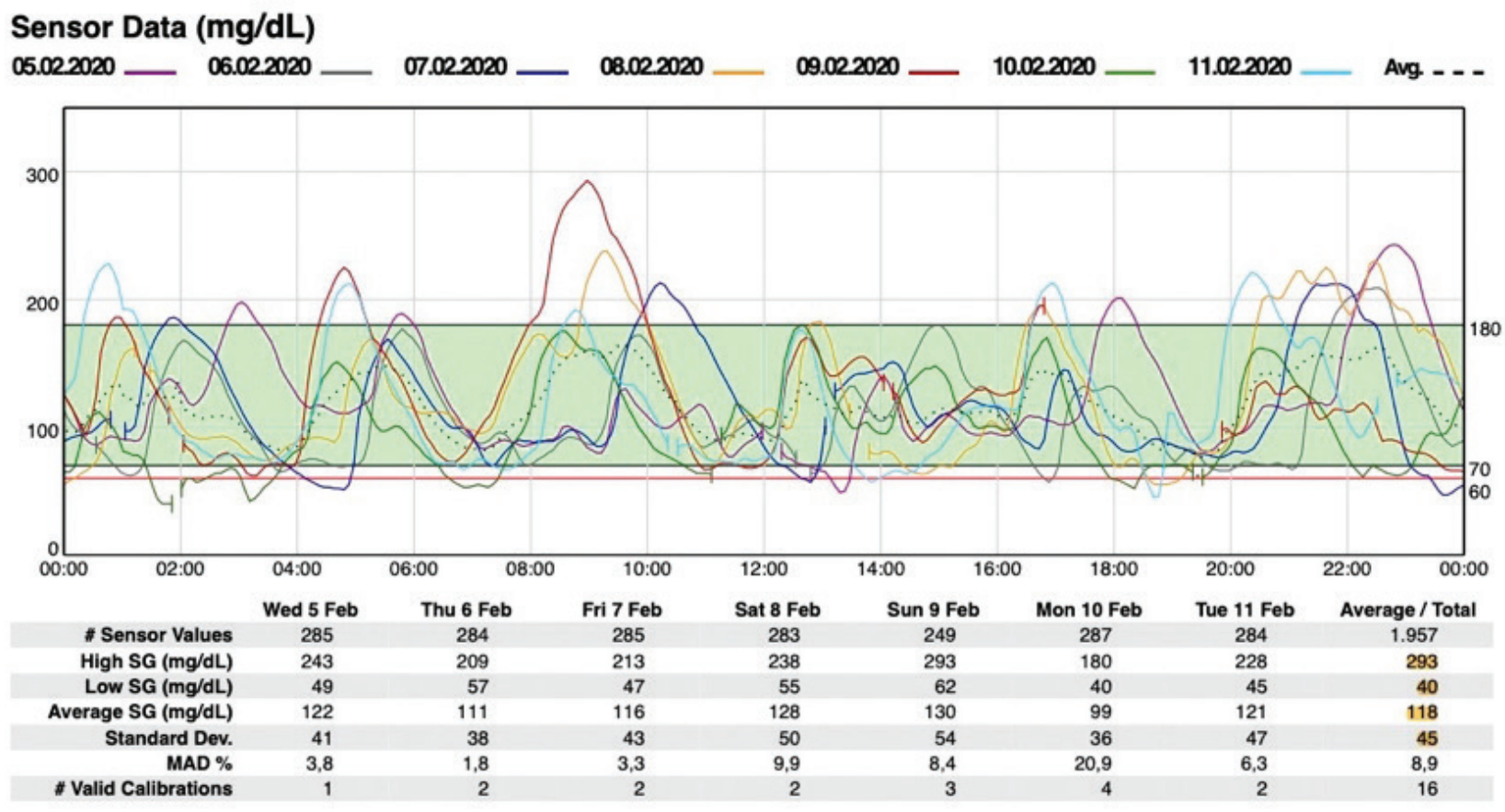

\section{Excursion Summary}

\begin{tabular}{|c|c|c|c|c|c|c|c|c|}
\hline & Wed 5 Feb & Thu 6 Feb & Fri 7 Feb & Sat 8 Feb & Sun 9 Feb & Mon 10 Feb & Tue 11 Feb & Average / Total \\
\hline \# Excursions & 5 & 2 & 5 & 5 & 4 & 4 & 7 & 32 \\
\hline \# High Excursions & 4 & 1 & 3 & 4 & 4 & 0 & 5 & 21 \\
\hline \# Hypo Excursions & 1 & 1 & 2 & 1 & 0 & 4 & 2 & 11 \\
\hline AUC Above Limit & 3,1 & 1,0 & 2,1 & 5,0 & 7,7 & 0,0 & 3,5 & 3,1 \\
\hline AUC Below Limit & 0,3 & 0,4 & 1,3 & 0,7 & 0,2 & 2,8 & 0,6 & 0,9 \\
\hline
\end{tabular}

\section{Duration Distribution (hh:mm)}
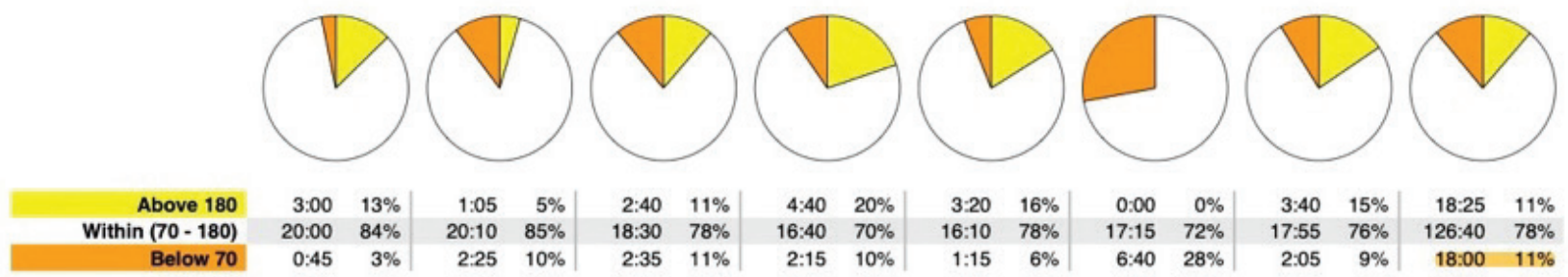

\begin{tabular}{rr|}
$2: 40$ & $11 \%$ \\
$18: 30$ & $78 \%$
\end{tabular}

$4: 40 \quad 20 \%$

$3: 20 \quad 16 \%$

\begin{tabular}{l|l|l|l|l|l}
\hline $0: 00$ & $0 \%$ & $3: 40$ & $15 \%$ & $18: 25$ & $11 \%$
\end{tabular}

$2: 35 \quad 11 \%$

$\begin{array}{rr}16: 40 & 70 \% \\ 2: 15 & 10 \%\end{array}$

\begin{tabular}{rr|}
$16: 10$ & $78 \%$ \\
$1: 15$ & $6 \%$
\end{tabular}

$\begin{array}{rr}17: 15 & 72 \% \\ 6: 40 & 28 \%\end{array}$

\begin{tabular}{l|l|r|r}
$17: 55$ & $76 \%$ & $126: 40$ & $78 \%$ \\
\hline
\end{tabular}

Figure 1. Continuous glucose monitoring system report: Before the addition of maltodextrin (it is noted that time in below range was $11 \%$, the ratio of below $<70 \mathrm{mg} / \mathrm{dL})$ 


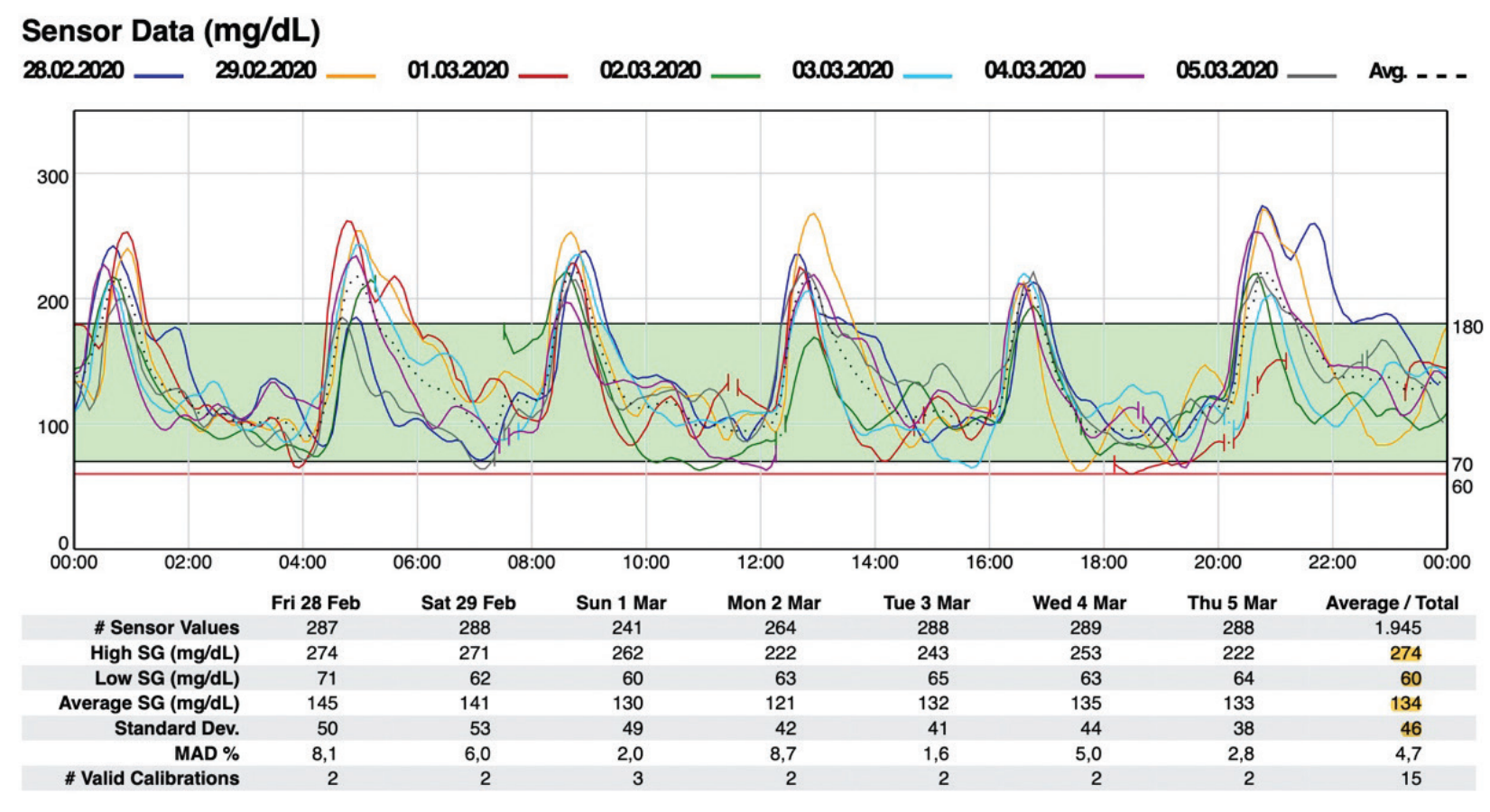

\section{Excursion Summary}

\begin{tabular}{|c|c|c|c|c|c|c|c|c|}
\hline & Fri 28 Feb & Sat 29 Feb & Sun 1 Mar & Mon 2 Mar & Tue $3 \mathrm{Mar}$ & Wed 4 Mar & Thu 5 Mar & Average / Total \\
\hline \# Excursions & 2 & 2 & 1 & 4 & 4 & 4 & 5 & 22 \\
\hline \# High Excursions & 2 & 2 & 1 & 4 & 4 & 4 & 5 & 22 \\
\hline \# Hypo Excursions & 0 & 0 & 0 & 0 & 0 & 0 & 0 & 0 \\
\hline AUC Above Limit & 9,2 & 10,3 & 6,5 & 2,9 & 4,4 & 5,3 & 3,1 & 6,0 \\
\hline AUC Below Limit & 0,0 & 0,1 & 0,3 & 0,1 & 0,0 & 0,1 & 0,1 & 0,1 \\
\hline
\end{tabular}

\section{Duration Distribution (hh:mm)}

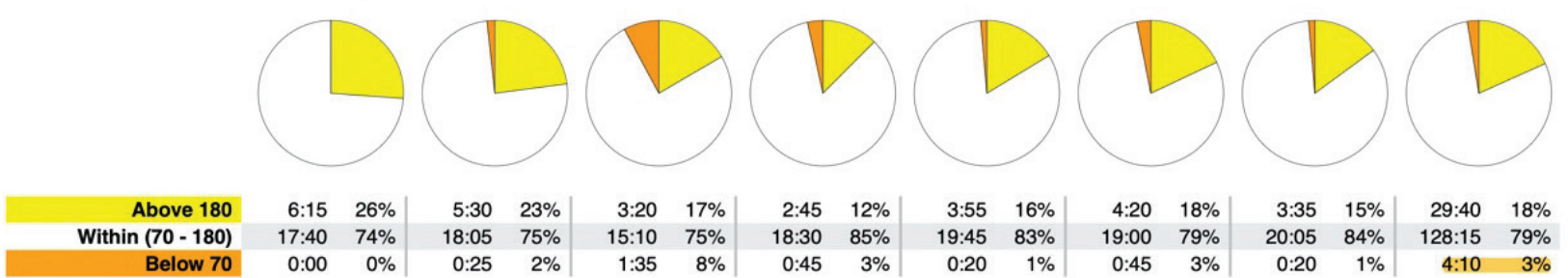

Figure 2. Continuous glucose monitoring system report: After the addition of maltodextrin (it is noted that time in below range was $3 \%$, the ratio of below $<70 \mathrm{mg} / \mathrm{dL}$ )

\section{Conclusion}

The management of $\mathrm{CHI}$ requires a multidisciplinary approach. Hypoglycemia can persist, even after a near-total pancreatectomy, especially in patients with diffuse form and potassium channel mutations. Our case suggests that the addition of maltodextrin in the early pre-op or post-op period may shorten hospitalizations, prevent complications, and even protect the patient from the side effects of treatments. However, more case series or case-control studies are needed in order to determine the efficacy of maltodextrin supplementation in the management of infants with $\mathrm{CHI}$.

\section{Ethics}

Informed Consent: The consent form was filled out by the parent.

Peer-review: Externally peer-reviewed.

\section{Authorship Contributions}

Surgical and Medical Practices: Yasemin Denkboy Öngen, Erdal Eren, Halil Sağlam, Concept: Yasemin Denkboy Öngen, 
Design: Halil Sağlam, Data Collection or Processing: Yasemin Denkboy Öngen, Erdal Eren, Analysis or Interpretation: Erdal Eren, Literature Search: Yasemin Denkboy Öngen, Erdal Eren, Halil Sağlam, Writing: Yasemin Denkboy Öngen, Erdal Eren, Halil Sağlam.

Financial Disclosure: The authors declared that this study received no financial support.

\section{References}

1. Roženková K, Güemes M, Shah P, Hussain K. The Diagnosis and Management of Hyperinsulinaemic Hypoglycaemia. J Clin Res Pediatr Endocrinol 2015;7:86-97.

2. Galcheva S, Al-Khawaga S, Hussain K. Diagnosis and management of hyperinsulinaemic hypoglycaemia. Best Pract Res Clin Endocrinol Metab 2018;32:551-573. Epub 2018 Jun 6

3. Arnoux JB, Verkarre V, Saint-Martin C, Montravers F, Brassier A, Valayannopoulos V, Brunelle F, Fournet JC, Robert JJ, Aigrain Y, Bellanné-Chantelot C, de Lonlay P. Congenital hyperinsulinism: current trends in diagnosis and therapy. Orphanet J Rare Dis 2011;6:63.

4. Adzick NS, De Leon DD, States LJ, Lord K, Bhatti TR, Becker SA, Stanley CA. Surgical treatment of congenital hyperinsulinism: Results from 500 pancreatectomies in neonates and children. J Pediatr Surg 2019;54:2732. Epub 2018 Oct 5
5. Demirbilek H, Hussain K. Congenital Hyperinsulinism: Diagnosis and Treatment Update. J Clin Res Pediatr Endocrinol 2017;9(Suppl 2):6987. Epub 2017 Dec 27

6. Xu A, Cheng J, Sheng H, Wen Z, Lin Y, Zhou Z, Zeng C, Shao Y, Li C, Liu L, Li X. Clinical Management and Gene Mutation Analysis of Children with Congenital Hyperinsulinism in South China. J Clin Res Pediatr Endocrinol 2019;11:400-409. Epub 2019 Jun 18

7. Ludwig A, Ziegenhorn K, Empting S, Meissner T, Marquard J, Holl R; Diabetes Patienten-Verlaufsdokumentationssystem (DPV) Group; Mohnike K. Glucose metabolism and neurological outcome in congenital hyperinsulinsm. Semin Pediatr Surg 2011;20:45-49.

8. Cappella M, Graziani V, Pragliola A, Sensi A, Hussain K, Muratori C, Marchetti F. Hyperinsulinemic Hypoglycaemia in a Turner Syndrome with Ring (X). Case Rep Pediatr 2015;2015:561974. Epub 2015 Apr 29

9. De Cosio AP, Thornton P. Current and Emerging Agents for the Treatment of Hypoglycemia in Patients with Congenital Hyperinsulinism. Pediatr Drugs 2019;21:123-136.

10. Corda H, Kummer S, Welters A, Teig N, Klee D, Mayatepek E, Meissner T. Treatment with long-acting lanreotide autogel in early infancy in patients with severe neonatal hyperinsulinism. Orphanet J Rare Dis 2017;12:108.

11. Hofman DL, van Buul VJ, Brouns FJ. Nutrition, Health, and Regulatory Aspects of Digestible Maltodextrins. Crit Rev Food Sci Nutr 2016;56:2091-100. 